Goldschmidt 2021 Abstract

https://doi.org/10.7185/gold2021.5304

\section{An Explosive Monogenetic Alkaline Volcanic Field on the SW Indian Ridge}

\section{HENRY J B DICK}

Woods Hole Oceanographic Institutuion

Presenting Author: hdick@whoi.edu

Geophysics and bathymetry collected by the RV Knorr in 1986 on the SW Indian Ridge between the DuToit and Andrew Bain FZ's (Takeuchi et al., 2010) reveal an explosive monogenetic volcanic field filling the rift valley and bordering rift mountains instead of the classic ridge morphology of lineated axial effusive MORB volcanism. Off-axis explosive volcanism dominated the region for $9 \mathrm{Ma}$. In the west there is magnetics and gravity evidence of relatively thick crust. There is evidence for subordinant effusive volcanism as well on the western segment. Limited geochemical data for the western ridge segment recovered a transitional suite of alkaline to subalkaline tholeiitic lavas. These samples appear to all be glassy pillow basalts with slightly enriched LREE patterns Peyve et al.(2017). It is not evident that volcaniclastics were recovered (or recognized), despite the explosive volcanic terrain.

The eastern segment also has a crater field that extends out into the rift mountains, but limited sampling and geophysical data show that the crust is thin and discontinuous with massive exposure of the mantle on the seafloor. The absence of an axial magnetic anomaly indicates that little or no recent effusive volcanism has occurred. Basalt and diabase from the north along the wall of the DuToit FZ found depleted MORB and highly LREE-enriched basalts, consistent with more extreme alkaline volcanism on the eastern segment. The change in character of the ridge from east to west represents a lateral gradient in mantle temperature, increasing away from the Andrew Bain FZ (Takeuchi et al., 2010), such that the depleted mantle contributes more substantially to formation of the crust to the west. While effusive volcanism is closely controlled by rifting in the shallow crust, the explosive volcanism is not, with a stochastic distribution of the vents. This indicates that it is sourced in the deep mantle, and transported at high velocity to erupt explosively on the seafloor, and as individual eruptions pass into an effusive stage, magma mixing with effusive tholeiitic melts within the crust then produce a spectrum of enriched to depleted compositions.
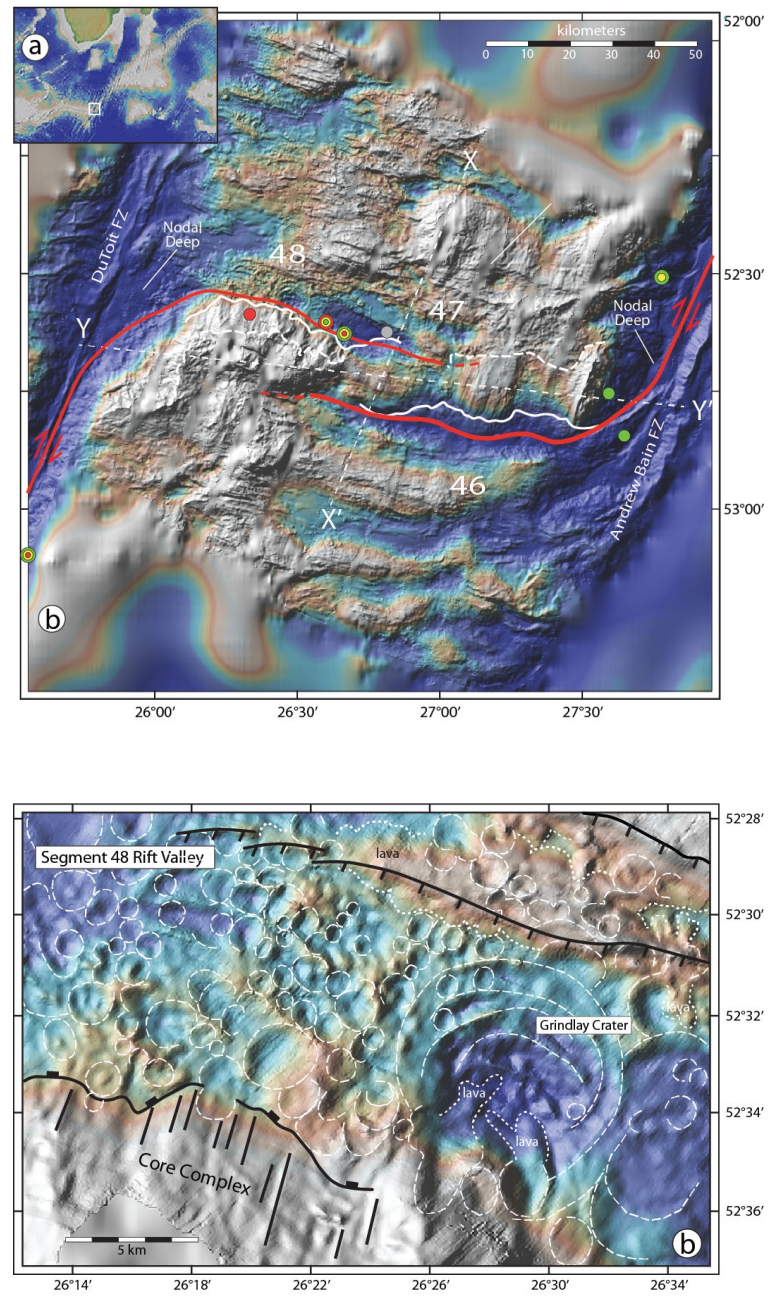